\title{
EDUCAR PELA PESQUISA NA DISCIPLINA DE SEMINÁRIO INTEGRADO: UM OLHAR DIFERENCIADO SOBRE O ENSINO MÉDIO NOTURNO
}

\author{
EDUCAR PARA LA INVESTIGACIÓN EN SEMINARIO INTEGRADO DE \\ DISCIPLINA: UNA MIRADA DIFERENCIAL EN LA NOCHE EDUCACIÓN \\ SECUNDARIA
}

\section{EDUCATION FOR RESEARCH IN THE INTEGRATED SEMINAR DISCIPLINE: A DIFFERENTIATED LOOK AT MIDDLE SCHOOL NIGHT}

\author{
Josué MICHELS ${ }^{1}$ \\ Gabriela Ribeiro BARBOSA ${ }^{2}$ \\ Maria Eloisa FARIAS ${ }^{3}$
}

RESUMO: O artigo tem a intenção de apresentar uma proposta de trabalho pautada pelo educar pela pesquisa, realizada com alunos do terceiro ano noturno do ensino médio politécnico de uma Escola Estadual do município de Camaquã - RS. A iniciativa deu-se em virtude da vontade de prover estimulo a alunos, em sua maioria trabalhadores, os quais, cansados da jornada de trabalho, acabam perdendo interesse pelos estudos. A metodologia utilizada consistiu em propiciar um ambiente de pesquisa em sala em aula, com proposição de atividades alicerçadas nos pressupostos do educar pela pesquisa. Ao término do processo, a coleta de dados foi realizada a partir de questionários e entrevistas. Após a análise dos dados coletados, o estudo demonstrou expectativas e dificuldades que emergiram dos alunos nas práticas de pesquisa, bem como, a importância da proposta do educar pela pesquisa, propiciando aos alunos autonomia no processo de construção do conhecimento.

PALAVRAS-CHAVE: Educar pela pesquisa. Ensino noturno. Seminário integrado.

RESUMEN: En este artículo se propone presentar un trabajo guiado por la educación a través de la investigación llevada a cabo con los estudiantes del tercer año de politécnicos altos nocturnos de un colegio público en la ciudad de Camaquã-RS. La iniciativa se llevó a cabo debido a la voluntad de ofrecer aliento a los estudiantes, en su mayoría trabajadores, que, cansado de la jornada de trabajo, pierden interés en los estudios. La metodología utilizada fue proporcionar una sala de investigación en el

1 Doutorando do Programa de Pós-graduação em Ensino de Ciências e Matemática PPGECIM da Universidade Luterana do Brasil ULBRA. Professor do Instituto Federal Sul-rio-grandense IFSUL. Email: jcmichelsbio@gmail.com

${ }^{2}$ Especialista em Ensino de Ciências Educar pela Pesquisa. Instituto Federal Sul-rio-grandense IFSUL. Email: gabinharb@gmail.com

3 Professora Doutora da Universidade Luterana do Brasil ULBRA. Programa de Pós-graduação em Ensino de Ciências e Matemática PPGECIM 
ambiente de la clase, con la propuesta de actividades basada en suposiciones de la educación a través de la investigación. Al final del proceso, la recogida de datos se llevó a cabo a partir de cuestionarios y entrevistas. Tras el análisis de los datos recogidos, el estudio mostró que las expectativas y dificultades que surgieron de los estudiantes en prácticas de investigación, así como la importancia de la propuesta de la educación mediante la investigación, proporcionando a los estudiantes con autonomía en el proceso de construcción del conocimiento.

PALABRAS CLAVE: Educación a través de la investigación. Cursos nocturnos. Seminario integrado.

ABSTRACT: The article intends to propose a work guided by education through research conducted with students of the third year of high night polytechnics of a state school in the city of Camaquã-RS. The initiative took place because of the desire to provide encouragement to students, mostly workers, who, tired of the working day, they lose interest in studies. The methodology used was to provide a research room in the classroom environment, with activities proposition grounded in assumptions of education through research. At the end of the process, data collection was carried out from questionnaires and interviews. After analyzing the data collected, the study showed expectations and difficulties that emerged from the students in research practices, as well as the importance of the proposal of education through research, providing students with autonomy in the knowledge construction process.

KEYWORDS: Education through research. Night courses. Integrated seminar.

\section{Introdução}

O ensino médio noturno, no Brasil, apresenta peculiaridades que impõem uma série de dificuldades aos processos de ensino e de aprendizagem, as quais contribuem significativamente para a evasão escolar (TOGNI e SOARES, 2007).

Muitas destas dificuldades comprometem o trabalho do professor que deseja promover uma aprendizagem realmente significativa com os alunos desse turno (RODRIGUES e HERÁN, 2000). Estes alunos, em sua grande maioria, são trabalhadores que chegam à escola após uma jornada de trabalho, cansados e desmotivados para aprender os conteúdos, por vezes desconectados da realidade em que vivem. Ainda, muitos carregam obrigações de pais ou mães de família e encontram-se distantes do ambiente escolar, apresentando grandes dificuldades para acompanharem as aulas.

Diante da falta de um planejamento adequado para o trabalho com o ensino médio noturno e de todas as dificuldades supracitadas, os professores, por conta própria, 
acabam buscando alternativas isoladas e obtendo inúmeras frustrações. Como consequência deste processo, estes educadores passam a cobrar o mínimo possível dos alunos, aprovando-os ano após ano, considerando que estes, por apresentarem condições sociais menos favorecidas, não irão almejar muito para seu futuro. Neste contexto, o ensino noturno promoveu a democratização do acesso à escola e o fortalecimento de mais uma divisão dentro da própria escola (KUENZER, 1988; RODRIGUES, 1995). "São trabalhadores que estudam" (ARROYO, 1997, p. 28), mas não é por acaso que buscam a escola. Esses alunos visam sem dúvida algo que lhes interessa: formação e informação que os auxiliem no dia-a-dia, na luta pela sobrevivência. Se a escola não lhes oferecer o que buscam, estes provavelmente se sentirão desmotivados, inviabilizando uma oportunidade de vida, seja pessoal ou profissional (CUNHA, 1998).

Conforme Kuenzer (2001), é preciso lançar um olhar diferenciado a esses alunos, pois em meio a tantas dificuldades encontradas, eles ainda persistem em frequentar a escola. Portanto, precisam encontrar significado na sua presença, vislumbrando no ambiente escolar a possibilidade de planejar novas metas e almejar novos horizontes.

A Escola onde estudam os alunos objeto do presente estudo realiza suas atividades educativas no período da noite, sendo a maioria dos alunos moradores dos bairros adjacentes. A escola não apresenta uma situação diferente da realidade nacional, chegando a obter um índice de reprovação/abandono de $54,9 \%, 38,9 \%$ e $10,7 \%$ no $1^{\circ}, 2^{\circ}$ e $3^{\circ}$ anos do ensino médio respectivamente (CENSO ESCOLAR, 2013). Além deste aspecto, os professores percebem um desinteresse crescente, apresentado ao longo do tempo de permanência escolar, e mesmo aqueles que conseguem concluir o ensino médio, acabam não buscando o ensino superior.

Dentre outros aspectos, acreditamos que o presente quadro apresenta uma íntima ligação com a falta de motivação dos alunos, em parte potencializada pela desvinculação das práticas educativas em relação ao seu cotidiano. Considerando que a estratégia de ensino tradicional em vigor tem sucumbido às expectativas, torna-se necessário, ao menos, a experimentação de uma proposta que possibilite uma melhor compreensão sobre a realidade vivenciada por estes alunos, e uma maior significação do seu cotidiano.

Neste contexto a proposta de educar pela pesquisa, com alunos do ensino médio noturno, vislumbra intervir na construção do conhecimento de cada aluno, dentro do 
contexto vivenciado. Com a presente proposta procuramos desenvolver potencialidades indispensáveis a todos: "aprender a aprender e saber pensar para intervir de modo inovador" (DEMO, 1997, p. 9). Sendo a pesquisa condição básica "por seu lado educativo emancipatório, sua marca de atitude cotidiana, sua viabilidade em qualquer pessoa, sua relação intrínseca com o conhecimento inovador” (DEMO, 1997, p. 53). A aplicação do educar pela pesquisa tem como princípio a construção do conhecimento de maneira reflexiva, possibilitando que os alunos assumam um papel de protagonismo na sua própria educação e por consequência na sua vida social.

Como enfatizam Wallon (2010) e Vygotsky (2001), através de suas pesquisas, o homem aprende ou adquire seus conhecimentos ao se relacionar com o outro. Ao deparar-se com o que o outro está a realizar surge um motivo para fazer o mesmo, ou seja, imitar para saber se também é capaz. Assim, o educar pela pesquisa, em sala de aula, surge como proposta de incentivo aos alunos do período noturno, possibilitando, através do questionamento reconstrutivo e da pesquisa como atividade cotidiana, o início de uma mudança.

"Ensinar não é transferir conhecimento, mas criar as possibilidades para a sua produção ou a sua construção" (FREIRE, 1996, p. 21). As aulas de seminário integrado podem envolver os alunos em projetos de pesquisa que possibilitem esta construção. Quando desafiados a construírem projetos e alternativas para solucionarem as dificuldades encontradas, na verdade, estão sendo provocados a desenvolverem suas estratégias que possibilitem a aquisição da autonomia. Segundo Moraes, Ramos e Galiazzi (2004, p. 17), “ajudar os estudantes na construção de seus projetos pessoais de vida e estimulá-los para que tenham suas iniciativas próprias poderia ser uma das funções da escola. Isso significa contribuir para a construção de sua autonomia".

Em meio ao ensino tradicional, adotado na imensa maioria das escolas públicas do país, surge a implantação, em 2012, do Ensino Médio Politécnico no Estado do Rio Grande do Sul, tendo como justificativa desenvolver um "projeto educacional que atenda as dificuldades do mundo do trabalho, mas que tenha na sua centralidade o indivíduo, a partir de uma proposta de formação integral" (RIO GRANDE DO SUL, 2011, p. 8). A proposta que foi apresentada no final de 2011, levando em consideração o Plano de Governo para o Rio Grande do Sul para o período de 2011/2014, a Lei de Diretrizes e Bases da Educação Nacional (LDB/96) e a Resolução sobre Diretrizes Curriculares para Educação Básica emitida pelo Conselho Nacional de Educação 
(CNE/CEB no 5/2012), tem como uma das finalidades "o processo que, integrado ao cotidiano da escola, garante a apropriação adequada da realidade, assim como projeta possibilidades de intervenção. Alia o caráter social ao protagonismo dos sujeitos pesquisadores" (RIO GRANDE DO SUL. 2011, p. 22).

A proposta traz uma série de modificações para o ensino médio, entre elas, a implantação do seminário integrado, que deve ser uma parte diversificada na aprendizagem, a partir da articulação de projetos de pesquisa, dando lugar a um trabalho interdisciplinar, sobre assuntos de interesse dos alunos, que aproxime o conhecimento escolar ao mundo do trabalho (RIO GRANDE DO SUL, 2011). Se bem estudada e aplicada na escola, com observação das características do ensino médio noturno, a proposta, certamente, agrega autonomia de aprendizagem ao educando:

\begin{abstract}
Os Seminários Integrados constituem- se em espaços planejados, integrados por professores e alunos, a serem realizados desde o primeiro ano e em complexidade crescente. Organizam o planejamento, a execução e a avaliação de todo o projeto político- pedagógico, de forma coletiva, incentivando a cooperação, a solidariedade e o protagonismo do jovem adulto. A realização dos seminários integrados constará na carga horária da parte diversificada, proporcionalmente distribuída do primeiro ao terceiro ano, constituindo- se em espaços de comunicação, socialização, planejamento e avaliação das vivências e práticas do curso (RIO GRANDE DO SUL, 2011, p. 26).
\end{abstract}

Diante das considerações realizadas, a partir do presente estudo, tivemos como objetivo investigar as expectativas e dificuldades de alunos do ensino médio politécnico noturno ao utilizar uma proposta de trabalho pautada pela pesquisa.

\title{
Metodologia:
}

O estudo, com caráter qualitativo, foi realizado a partir das práticas desenvolvidas na disciplina de seminário integrado, em dois períodos semanais, ao longo do segundo semestre de 2015. A disciplina foi ministrada para duas turmas do terceiro ano do ensino médio politécnico noturno, de uma escola estadual de Ensino Médio, no município de Camaquã-RS, totalizando um universo de setenta alunos.

Os pressupostos do educar pela pesquisa, com ênfase nos princípios que caracterizam a pesquisa no aluno (DEMO, 2011), nortearam os diferentes momentos de construção do conhecimento a partir da pesquisa. Os alunos investigaram, em grupos, 
temas de seu interesse, seguindo três momentos ao longo da proposta: questionamento, construção dos argumentos e comunicação (MORAES, GALIAZZI e RAMOS, 2002).

Os meses de agosto, setembro e outubro foram destinados à construção dos questionamentos e construção dos argumentos. Nestes momentos, o ambiente de pesquisa obteve proporções cada vez maiores, transformando a sala de aula num espaço motivador e propício para a pesquisa científica. Para tanto, por iniciativa dos alunos, foram vivenciadas atividades individuais e/ou em grupos, como: visitas à biblioteca; leituras; produção textual autoral; coleta de dados nas fontes bibliográficas e internet; elaboração de instrumentos de pesquisa - questionários e entrevistas -, aplicados em diferentes segmentos da comunidade Camaquense, conforme o foco da pesquisa dos grupos. O mês de novembro foi destinado para lapidação da comunicação, escrita e oral. Foram realizados dois dias de apresentações orais, por um total de doze grupos, para uma banca composta pelos docentes que atuam com os terceiros anos.

A coleta de dados foi realizada a partir de observações e anotações ao longo dos processos supracitados, de questionários e entrevistas. Os questionários foram aplicados a todos os alunos, onde procuramos caracterizar o perfil dos alunos participantes do estudo. A entrevista foi aplicada em cinco grupos, escolhidos de maneira aleatória. A aplicação deste instrumento foi realizada em grupo, sendo gravada e transcrita para posterior análise.

Sucedendo a coleta de dados deu-se início à decomposição das informações presentes nos questionários e entrevistas pela técnica de análise de conteúdo, segundo Bardin (2011). A técnica se constitui nas etapas: pré-análise, a exploração do material, o tratamento dos resultados obtidos e a interpretação, visando à categorização das respostas escritas, com base em suas similaridades.

Os grupos entrevistados foram codificados em G1, G2, G3, G4 e G5, seguindo a ordem em que as entrevistas foram realizadas.

Foi explicado e assinado um termo de consentimento livre esclarecido - TCLE, onde ficaram esclarecidos os objetivos do estudo, bem como a garantia de sigilo aos participantes da amostra.

\section{Resultados e discussões:}

Ao examinar as etapas já concretizadas - Utilização da metodologia do educar pela pesquisa em sala de aula; Aplicação de questionários e Entrevista com os grupos - 
foi possível selecionar algumas informações relevantes para traçar um perfil mais adequado dos alunos do ensino médio noturno.

Tabela 1: Perfil dos alunos do estudo

\begin{tabular}{|c|c|c|}
\hline Item & Respostas fornecidas & Porc. \\
\hline \multirow{2}{*}{ Sexo } & Masculino & $57 \%$ \\
\hline & Feminino & $43 \%$ \\
\hline \multirow{2}{*}{ Reprovação no ensino médio } & Não reprovaram & $77 \%$ \\
\hline & Reprovou & $23 \%$ \\
\hline \multirow{2}{*}{ Faixa etária } & Entre 16 a 18 anos & $88,37 \%$ \\
\hline & Mais de 18 anos & $11,63 \%$ \\
\hline \multirow{5}{*}{ Renda familiar } & Até três salários minimos & $40,38 \%$ \\
\hline & Até dois salários minimos & $38,46 \%$ \\
\hline & Menos de um salário mínimo & $11,53 \%$ \\
\hline & Mais de cinco salários mínimos & $5,76 \%$ \\
\hline & Até cinco salários mínimos & $3,84 \%$ \\
\hline \multirow{3}{*}{ Ocupação } & Está trabalhando & $73 \%$ \\
\hline & Já trabalhou durante o ensino médio & $23 \%$ \\
\hline & Nunca trabalhou & $4 \%$ \\
\hline \multirow{2}{*}{$\begin{array}{l}\text { A familia depende da sua } \\
\text { renda }\end{array}$} & Não & $79 \%$ \\
\hline & $\operatorname{Sim}$ & $21 \%$ \\
\hline \multirow{5}{*}{ Motivação para estudar } & Futuro melhor & $40 \%$ \\
\hline & Cursar faculdade & $26 \%$ \\
\hline & Concluir ensino médio & $15 \%$ \\
\hline & Conseguir emprego melhor & $11 \%$ \\
\hline & Ajudar a família & $8 \%$ \\
\hline
\end{tabular}

Fonte: elaboração própria. * (Salário mínimo nacional em 2015: R \$788,00)

A tabela acima mostra que a maior parte dos alunos envolvidos neste trabalho é composta de jovens menores de dezoito anos de idade. Junto a isso está o fato de que, não só os menores, mas a grande maioria do noturno, está envolvida em atividades laborais com objetivos financeiros. Esse dado conduz a pensar que se opta pelo ensino médio noturno visando uma conciliação do estudo com o trabalho. E em face disso, pode-se ainda supor que haja uma escala de valores para os estudantes em questão, onde se elege o trabalho em detrimento da aprendizagem - e com apenas $21 \%$ deles ajudando sua família.

Quanto à renda familiar, aproximadamente $50 \%$ das famílias desses jovens vivem com apenas dois salários mínimos, sendo que quase $12 \%$ deles sobrevivem com menos de um salário e, por isso, pode-se notar a necessidade desses alunos frequentarem o ensino médio à noite para conseguirem trabalhar durante o dia, pois são oriundos de famílias com baixa renda.

Desses jovens, apenas $26 \%$ são motivados a estudar para dar continuidade aos estudos, sonhando cursar uma faculdade. Os demais, 40\%, almejam um futuro melhor 
sem definir ou descrever o que seja, muito provavelmente passar a uma situação com uma boa segurança financeira. Ainda, distribuídos em 34\%, estão outros objetivos: concluir o ensino médio, conseguir um emprego melhor e ajudar aos familiares. Esses dados corroboram o pensamento de Sposito (1989, p. 102):

Discriminados economicamente, sofrendo as desigualdades do sistema escolar, esses alunos acreditam que a posse do 'saber', ainda considerado como algo obscuro e até mágico, lhes daria condições de melhor enfrentamento e talvez de superação de sua condição social.

Cabe salientar que o acesso ao ensino superior em Camaquã - RS é regido unicamente por faculdades particulares e a grande maioria dos alunos, de acordo com a renda informada, apresentam dificuldades de deslocamento para outros municípios, onde poderiam encontrar um ensino público e gratuito em nível de graduação.

\section{Análise das entrevistas dos envolvidos a partir de suas vivências}

Para maior compreensão das discussões das entrevistas, segue abaixo a pergunta feita ao grupo e a tabela com informações a respeito das principais categorias e identificação dos grupos que se manifestaram:

Tabela 2: pontos positivos e negativos do trabalho em grupo

\begin{tabular}{|c|c|c|}
\hline Categoria & Subcategoria & Grupo \\
\hline \multirow{4}{*}{ Pontos Positivos } & Troca de idéias & $1,2,3,4$ e 5 \\
\hline & União do grupo & 1,2 e 5 \\
\hline & Escolha de grupo por afinidade & 1 \\
\hline & Comunicação entre o grupo & 5 \\
\hline \multirow{5}{*}{ Pontos negativos } & $\begin{array}{l}\text { Falta de horários para reuniões devido à } \\
\text { ocupação do tempo com trabalho remunerado }\end{array}$ & $1,3,4$ e 5 \\
\hline & $\begin{array}{l}\text { Colaboração insuficiente e desinteresse de } \\
\text { alguns elementos do grupo }\end{array}$ & 2,3 e 4 \\
\hline & Divergência de opiniões sem chegar a consenso & 2 e 5 \\
\hline & Baixa comunicação entre os colegas & 3 \\
\hline & Cansaço do dia de trabalho & 5 \\
\hline
\end{tabular}

Fonte: elaboração própria. 
Quando questionados sobre os pontos positivos e negativos da realização dos trabalhos, os estudantes, de todos os grupos, elencaram a troca de ideias. Informando assim, que ao se trabalhar com outra pessoa, o pensamento singular do outro se torna um meio de enriquecimento e construção do conhecimento mútuo, pois “[...] ajuda a conversar com os outros, a perguntar. Tu acaba acumulando conhecimentos com a comunicação.” (G5).

Ainda na esfera de pontos positivos, três dos grupos entrevistados mencionaram que a união criada entre os componentes do grupo foi um fator de solução de diversos problemas na pesquisa, onde os alunos destacaram a motivação que advinha dos demais colegas, por exemplo: "Desde que eu estudo aqui, foi a primeira vez que a gente montou um grupo de verdade e fez alguma coisa [...]” (G5). Observamos que o trabalho em grupo pode ser um estímulo, desde que haja produtividade e evolução individual, com a capacidade de produção do coletivo (DEMO, 2003).

Nos pontos negativos destaca-se a falta de horários para reuniões fora da escola. Isso se deve à ocupação do tempo da maioria dos alunos do noturno no trabalho remunerado durante o dia e, sendo assim, a conciliação de horários diurnos se torna uma tarefa quase impossível. A dedicação aos estudos se restringe às horas disponíveis em sala de aula ou no tempo reservado ao descanso semanal (SPOSITO, 1989). As manifestações dos alunos, atribuindo ênfase a esse aspecto, indicam existir o interesse em investir mais tempo com pesquisa, ou uma queixa que aponta o trabalho como um limitador da atividade escolar.

Demo (2003) enfatiza que o trabalho em conjunto deve promover individualidade e solidariedade. Porém, dentre os pontos negativos apontados pelos alunos está a insuficiente colaboração e o desinteresse de alguns elementos do grupo "Negativo é quando o cara não ajuda, fica lá sem se envolver e ganha nota de graça [...]” (G2) - reclama o colega diante dessa situação. Salientaram que, por isso, a produção do coletivo poderia ter sido mais produtiva, e que houve sobrecarga de quem assumiu as responsabilidades. Daí pode-se questionar se o grupo contou com a presença de elementos simplesmente desmotivados, ou com a carência da formação de lideranças no sistema educacional.

Tabela 3: Dificuldade para pesquisar 


\begin{tabular}{l|l}
\hline \multicolumn{1}{c|}{ Categoria } & \multicolumn{1}{c}{ Grupos } \\
\hline Interpretar para conseguir escrever & $1,2,4$ e 5 \\
\hline Novidade & 3,4, e 5 \\
\hline Receios & 1,3 e 4 \\
\hline Coleta de dados & 2 e 5 \\
\hline
\end{tabular}

Fonte: elaboração própria

A respeito das dificuldades encontradas no processo de realização das pesquisas, cabe destacar a de interpretar e produzir textos. Essa está diretamente ligada com a complexa passagem da letra científica escrita ou falada nas diversas fontes de consulta para a linguagem do contexto em que o aluno está inserido. "A dificuldade que a gente encontrou seria essa: interpretar o que a gente estava lendo pra conseguir escrever. Porque todo nosso trabalho foi feito escrevendo com nossas palavras [...]" (G1). Conseguir transpor ideias de teóricos, não simplesmente copiá-las para a pesquisa escrita, mostrou-se um obstáculo a ser vencido pelos alunos, acostumados com a tradicional cópia dos livros didáticos ou páginas da internet "[...] e tu fazer só o trabalho teórico para entregar, tu copia e cola [...]” (G2). A produção textual aparece, sobremaneira, como uma ferramenta eficaz para organizar o pensamento e construir a aprendizagem. Em tempo, a percepção desta dificuldade, demonstra que os alunos perceberam e enfrentaram o desafio de compreensão e elaboração. Trata-se de um indício de superação do ensino de transmissão, pois, "aparecendo a elaboração própria, torna-se visível o saber pensar e o aprender a aprender" (DEMO, 2011, p. 29).

Outra dificuldade levantada na entrevista diz respeito ao método mais adequado de aproximar-se dos melhores resultados, ou seja: qual a melhor forma de se obter a verdade dos fatos? Ao confrontar os resultados de suas buscas com as definições provenientes dos estudos dos autores pesquisados, obtiveram resultados diferentes que despontaram em reflexões interessantes como essa:

Quando nós fomos comparar as nossas coletas de dados com os teóricos, a gente achou muita diferença. O que a gente viu na nossa sociedade aqui é muito diferente do que se escreve em livros $e$ pesquisas fora do país. A gente não entendeu direito essa parte. Tanto que a gente não se baseou tanto em alguns escritores porque era muito fora da realidade do que a gente tinha [...] (G5). 
A partir disso, pode-se perceber a presença do diálogo entre os métodos estabelecidos pelos pesquisadores consagrados e os resultados encontrados pelos alunos pesquisadores. Ao afirmarem que a realidade deles é “[...] muito diferente [...]” (G5), demonstraram condições de questionar e avaliar seus próprios métodos e, também, a realidade analisada por meio de novas pesquisas. Fator de suma importância em um processo que visa o desenvolvimento da autonomia de maneira reflexiva. Ainda, como afirma Carvalho (1999), o questionamento e a crítica como fundamentais dentro da pesquisa, que busca explicações do objeto estudado, despertando o espírito científico nos alunos.

Instaurar no meio discente essa metodologia de ensino no último ano no ensino médio poderia ser vista como uma iniciativa totalmente positiva? Para essa questão é interessante considerar o elemento surpresa mencionado nas palavras da aluna:

A gente nunca tinha feito um projeto de pesquisa, nunca nenhum professor tinha pedido uma pesquisa pra gente. Então este ano foi meio que uma coisa diferente. Um bicho de sete cabeças. Realmente as outras professoras pediam só um trabalhinho, sabe? Por trimestre, no caso. E a gente, tá, entregava aquilo e pronto [...] (G4).

Em geral, os grupos relacionaram o método descrito no presente artigo como uma dificuldade, "Um bicho de sete cabeças [...]” (G4). Queixaram-se da falta de pesquisa em sala de aula, por não realizarem nenhuma dinâmica parecida como essa antes. A introdução da pesquisa como metodologia gerou incertezas e receios nos alunos, até porque eles viram-se diante da necessidade de buscar o conhecimento, vencer o desafio por meio do seu próprio esforço, como protagonistas do próprio aprendizado (DEMO, 1997).

As palavras da aluna acima, já no seu último ano do ensino médio, apresentam uma importante reflexão: o que está sendo feito, no cotidiano escolar, para propiciar aos alunos o desenvolvimento do autêntico desejo de conhecer o mundo e a vida de maneira significativa.

Tabela 4: Pesquisa como auxiliadora do aprendizado 


\begin{tabular}{l|l}
\hline \multicolumn{1}{c|}{ Categoria } & \multicolumn{1}{c}{ Grupos } \\
\hline Conhecimento & $1,2,3$ e 5 \\
\hline Aumento de interesse pela aula & 1,4 e 5 \\
\hline Aprofundamento de conceitos & 2,4 e 5 \\
\hline Escrita & 1 e 5 \\
\hline Na continuidade dos estudos & 1 e 3 \\
\hline Desinibição/falar em público & 5 \\
\hline
\end{tabular}

Fonte: elaboração própria

Os alunos perceberam que a pesquisa os auxiliou no aprendizado, referindo-se à construção do conhecimento. Nesse sentido, os alunos perceberem que estavam constituindo seu próprio aprendizado, aprender a aprender (DEMO, 1997), e não simplesmente ganhando respostas prontas e acabadas pelo professor. Ainda, que, no início houvesse o sobressalto da novidade (GALIAZZI, 2000), no desenvolver das aulas reconheceram a prática da pesquisa como fonte de aquisição de conhecimento: "Então, no caso, tu vai ter que ir correr atrás do teu próprio conhecimento, tu vai colocar na tua mente, não vai ser outra pessoa, a gente adquire conhecimento e fica pra gente $[\ldots] "(\mathrm{G} 2)$.

Outro elemento que não poderia deixar de ser mencionado foi $o$ aprofundamento de conceitos. Com as ferramentas de pesquisa formadas em sala de aula, houve um despertar do lado investigativo do educando, que o capacitou para argumentar, criticar e avaliar o tema estudado, indo além do que já era conhecido por eles, graças à habilidade de reconstrução de conhecimentos.

Agrega-se a este fato o aumento de interesse pela aula. No esforço por buscar o conhecimento nas atividades estabelecidas, os alunos descobriram, no tempo de aula, uma vertente de oportunidades para o benefício dos seus objetos de estudo, esclarecendo-os seja por meio da consulta bibliográfica, seja pelo diálogo interpessoal dos grupos e o auxílio da professora. Decorreu daí que o ambiente saudável de pesquisa motivou os alunos individualmente: "Eu acho que sou o aluno mais desinteressado desta escola. E realmente eu me interessei em fazer esse trabalho, porque, olha só, a gente tinha uma boa equipe, tinha o que fazer [...]" (G5). 
Tabela 5: Diferenças entre a realização de atividades de seminário integrado atual e em anos anteriores

\begin{tabular}{l|l}
\hline Categoria & Grupos \\
\hline Novidade & $1,2,3,4$ e 5 \\
\hline Apresentação à banca & $1,2,3$ e 5 \\
\hline Sair da teoria & $2,3,4$ e 5 \\
\hline Mais cobrança & 1,2 e 4 \\
\hline Desenvolvimento de habilidades & 1 e 5 \\
\hline Maior envolvimento do aluno & 1 e 2 \\
\hline
\end{tabular}

Fonte: elaboração própria

Quando questionados sobre o que realizaram de diferente nas aulas de seminário integrado do terceiro ano em relação à mesma disciplina em anos anteriores, destacam-se três respostas: novidade, apresentações à banca e a passagem da teoria à realização da pesquisa.

Aqui os alunos recorrem novamente à pesquisa em sala de aula como uma novidade: “A gente não fazia projeto, a gente não pesquisava, só escrevia [...]” (G5). Uma vez que essa disciplina de seminário integrado foi implantada no Estado do Rio Grande do Sul, nas aulas do ensino médio politécnico desde 2012, com objetivo de intermediar a diversidade na aprendizagem, através da articulação de projetos de pesquisa, fica o questionamento de como a disciplina está sendo ministrada e se a implantação do Ensino Politécnico no Estado do Rio Grande do Sul ocorreu com a devida preparação dos professores.

A apresentação à banca foi mencionada pelos alunos como grande diferencial, incentivando-os a estarem bem preparados, uma vez que deveriam falar sobre suas pesquisas sem recorrerem à leitura de papéis: "No decorrer dos três anos aqui foi a primeira vez que a gente apresentou um trabalho sem nenhum auxílio, sem nenhum papel, nada [...]" (G1). Com novos entendimentos e um olhar diferente do inicial, os alunos se envolveram no seminário comunicando aos demais colegas o que verdadeiramente aprenderam (MORAES, GALIAZZI e RAMOS, 2004), surpreendendo-se com as habilidades desenvolvidas: "[...] eu até mesmo me surpreendi por conseguir falar [...]" (G5).

No tocante ao sair da teoria, os alunos fizeram referência à proposta da realização da pesquisa científica, utilizando-se de conceitos que antes eles só copiavam 
e não sabiam onde os conteúdos seriam utilizados. Engajados na realização dos projetos e nas suas apresentações, compreenderam que a teoria deu lugar a prática: "O primeiro e o segundo (anos do ensino médio) era só conteúdo, a gente praticamente não fez. nada. A gente colocou o conteúdo em prática só agora no terceiro ano [...]”. (G2). Possibilitando, de maneira efetiva, a importante aproximação entre teoria e prática (GALIAZZI, 2000).

Tabela 6: Atuação do professor

\begin{tabular}{l|l}
\hline \multicolumn{1}{c|}{ Categoria } & \multicolumn{1}{c}{ Grupos } \\
\hline Liberdade/Autonomia & $1,2,3,4$ e 5 \\
\hline Auxilio & $1,3,4$ e 5 \\
\hline Comprometimento & 1 e 4 \\
\hline Incentivo & 1 e 4 \\
\hline
\end{tabular}

Fonte: elaboração própria

Questionados sobre suas percepções com relação à atuação do professor da disciplina, no decorrer das aulas ministradas, os grupos foram unânimes em perceberem a autonomia concedida no desenvolver das atividades, possibilitando aos alunos criarem caminhos próprios de aprender: "O professor te deu o início, e tu tinha que escolher como e de que maneira tu iria trabalhar [...]" (G3). O "desenvolvimento da autonomia intelectual" (DEMO, 2003, p. 86) ocorreu no momento em que perceberam a liberdade propiciada pelo professor e utilizaram-na com o propósito da aprendizagem.

Os alunos salientaram que não acharam difícil trabalhar de modo mais independente, pois criaram seus próprios meios de chegar ao conhecimento, tornando o aprendizado significativo e prazeroso:

O professor deu as cartas e a gente fez o jogo. Não era aquela coisa de dizer: "Tem que ser assim". Foi dadas as regras, mas tu fazia, digamos, dentro das regras, do teu jeito. Então ficou uma coisa gostosa de trabalhar [...]. (G2)

Os alunos perceberam o professor como um mediador, fazendo-os refletirem através de questionamentos e mostrando-se sempre disponível para auxiliálos, corroborando a fala de Freire, (2010, p. 47) de que "ensinar não é transferir conhecimento, mas criar as possibilidades para a sua própria produção ou a sua construção". 
Tabela 7: Como notaram o aprendizado

\begin{tabular}{l|l}
\hline \multicolumn{1}{c|}{ Categoria } & \multicolumn{1}{c}{ Grupos } \\
\hline Desinibição & 1,2 e 4 \\
\hline Leitura e escrita & 1,4 e 5 \\
\hline Compartilhar conhecimentos & 1 e 5 \\
\hline Formação de opinião / ideias próprias & 1 e 2 \\
\hline Prática de pesquisa & 5 \\
\hline Outras disciplinas & 5 \\
\hline
\end{tabular}

Fonte: elaboração própria

Quando indagados sobre como notaram a ocorrência de aprendizado durante as aulas e como se deu, foi apontada, pela maioria dos grupos, a desinibição em se expressar oralmente, um legado das apresentações:

No meu caso, como sou muito tímido, foi bem complicado, até na hora de apresentar. Porque eu dei uma gaguejada no começo [...] mas depois saiu normal - como se aquilo já tivesse entrado na minha cabeça, aí eu consegui apresentar normal e fui me soltando. E isso me ajudou bastante [...]. (G4)

Mesmo sentindo-se expostos, concordaram que a tarefa os motivou a construir argumentos contundentes para o momento da banca. "[...] tenho que fazer da minha cabeça, porque durante a apresentação se o professor perguntasse o que estava escrito, eu saberia responder [...]”. (G2).

Elencaram também como aprendizado a formação de ideias próprias, compartilhamento de conhecimento, bem como a leitura e a escrita. Sobre a formação de ideias próprias e o compartilhamento do conhecimento, segundo Moraes e Galiazzi (2002), estes momentos fazem parte do processo de questionamento reconstrutivo, composto ainda pelo questionamento, construção de argumentos e comunicação. "No decorrer das aulas, nós fomos vendo que deveríamos colocar a nossa opinião, as nossas ideias, de acordo com o que a gente pesquisou [...]” (G1). Com seus argumentos criados, após um primeiro momento, os alunos passaram através da comunicação a trocar ideias sobre esses argumentos, que poderiam ser refutados pelo grupo, fazendo surgir novos questionamentos: "Uma optava em uma coisa, a outra argumentava em outra, e a gente foi se ajudando [...]” (G1). 
A leitura e a escrita também relatadas pelos grupos, como forma de aprendizado, deu-se no instante em que o aluno passou a ler, não para fazer uma cópia ou memorização, e sim, para ler e escrever com o significado de reconstruir (DEMO, 1997). Essa transformação do entendimento revela-se nestas palavras: "Aprendi que, a gente lendo e escrevendo e procurando as coisas, tu aprende e tu nem se dá conta [...]" (G4).

Tabela 8: Descrição de uma aula significativa

\begin{tabular}{l|l}
\hline \multicolumn{1}{c|}{ Categoria } & \multicolumn{1}{c}{ Grupos } \\
\hline Debate de ideias que façam pensar & $1,2,3$ e 4 \\
\hline Motivação & $1,2,4$ e 5 \\
\hline Atividade de apresentação & 1,2 e 5 \\
\hline Valorização do aluno & 1,2 e 4 \\
\hline Quebrar a rotina & 2,3 e 4 \\
\hline
\end{tabular}

Fonte: elaboração própria

A última pergunta indagava os grupos sobre o que seria aula significativa, e as principais elucidações foram: uma aula que faça pensar, motivando e valorizando o aluno, e quebre a rotina. Essas respostas sugerem que o aluno anseia por ter seu espaço dentro da sala de aula, para que possa formular suas opiniões e discuti-las com os demais: "Que faz o aluno correr atrás do seu próprio estudo, faz desafiar, faz ele pensar $[\ldots]$ " (G2). Fica nítida a necessidade dos alunos sentirem-se motivados dentro da sala de aula, pois "educar é sobretudo motivar" (DEMO, 2006, p.16).

Entende-se, portanto, a aula significativa como um modelo dinâmico, onde o professor não é sempre o detentor do conhecimento, e isso é perceptível na resposta: "Dar espaço para a gente mostrar o que a gente sabe [...]" (G2). O aluno coloca-se como alguém que dispõe de um certo teor de conhecimento e necessita de espaço para expressá-lo. Logo se percebe o aluno não como "tábula rasa" (DEMO, 2000, p.32) e sim sujeito com ideias e explicações próprias sobre o mundo que o cerca.

Ao término da última questão foi perguntado aos grupos se as aulas de seminário integrado tinham sido significativas. As respostas apareceram de forma positiva: " $A$ gente aprendeu um com o outro, deu espaço pra mostrar o que a gente sabia, não só ficar copiando do quadro [...]" (G5). Portanto, de acordo com a proposta de gerar um ambiente voltado à pesquisa, embasando-se nas respostas dos alunos, em relação às diversas questões envolvendo dificuldades e aprendizagens experimentadas durante o 
processo, visto que declararam ser metodologia nova, entende-se que houve bom êxito do projeto segundo a proposta almejada.

\section{Considerações Finais}

Em vista dos argumentos observados, conclui-se que utilizar a metodologia da pesquisa com alunos do ensino médio noturno possibilitou aos mesmos uma nova perspectiva da construção do conhecimento, através da autonomia, da pesquisa do professor e aluno, do questionamento reconstrutivo, da argumentação e da escrita. Mesmo não havendo a participação ativa de todos os alunos, como mencionado nas discussões, uma parte considerável dos estudantes se envolveu na prática de elaborar e aplicar projetos de pesquisas e, em tempo, sentiu-se motivada com o feito.

Outro aspecto que merece especial consideração diz respeito à constatação da maioria dos alunos de que na disciplina de seminário jamais havia vivenciado uma experiência verdadeiramente de pesquisa. Em outrora, alguma dificuldade, como falta de subsídios para pesquisa, fontes de consulta, falta de tempo e motivação. Entretanto, mesmo com todas as limitações apresentadas pelos alunos, a atividade ocorreu com o máximo de exigência que o limite permitia, sendo possível, ao final da atividade, a concretização de um seminário, com bom nível de argumentações construídas pelos alunos.

Acreditamos na urgente necessidade de novas práticas educacionais que visem motivar os alunos do ensino noturno, para que esses consigam vislumbrar na escola um local agradável, onde o conhecimento é realizável e favorável a um futuro promissor.

\section{Referências}

ARROYO, M. G. Da escola coerente à escola possível. São Paulo: Loyola, 1997.

BARDIN, L. Análise de conteúdo. São Paulo: Edições 70. 2011.

BRASIL. Lei de Diretrizes e Bases da Educação Nacional. Lei número 9394, 20 de dezembro de 1996. 
Diretrizes Curriculares Nacionais para o Ensino Médio. Conselho

Nacional de Educação (CNE). Resolução nº 2, de 30 de janeiro de 2012.

CARVALHO, A. M. P. Uma Investigação na formação continuada dos professores: a reflexão sobre as aulas e a superação de obstáculos. In: ENCONTRO NACIONAL DE PESQUISA EM EDUCAÇÃO EM CIÊNCIAS, 2., 1999, Valinhos, SP. Atas, Valinhos: ABRAPEC, 1999.

CENSO ESCOLAR, 2013. Disponível em: <http://www.qedu.org.br/escola/256730eeem-joao-paulo-ii/taxas-rendimento>. Acesso em: 21 jan. 2016.

CUNHA, L. A. Ensino Médio e Ensino Profissional: da fusão à exclusão. In: Reunião Anual da ANPED, 20, Caxambu- MG. Atas, Caxambu:AMPED, 1998.

DEMO, P. Pesquisa e construção de conhecimento: metodologia científica no caminho de Habermas. 4. ed. Rio de Janeiro: Tempo Brasileiro, 1997.

DEMO, P. Educar pela pesquisa. 6. ed. Campinas: Autores Associados, 2003.

DEMO, P. Pesquisa: princípio científico e educativo. 12. ed. São Paulo: Cortez, 2006.

DEMO, P. Educar pela Pesquisa. 9.ed. Campinas: Autores Associados, 2011.

FREIRE, P. Pedagogia da autonomia: saberes necessários à prática. 41 ed. São Paulo: Paz e Terra, 2010.

GALIAZZI, M. do C.; MORAES, R. Educação pela pesquisa como modo, tempo e espaço de qualificação da formação de professores de ciências. Ciência \& Educação, v. 8 , n. 2, p. 237-252, 2002.

GALIAZZI, M. C. Educar pela pesquisa: espaço de transformação e avanço na formação inicial de professores de Ciências. Porto Alegre, 2000. Tese (Doutorado em Educação) - Faculdade de Educação, Pontifícia Universidade Católica do Rio Grande do Sul, 2000.

KUENZER, A. Z. "A escola de 2. ${ }^{\circ}$ grau na perspectiva do aluno trabalhador", in Cadernos Cedes, p. 48-55, 1988.

KUENZER, A. Z. A. Z. Ensino médio e profissional: as políticas do Estado neoliberal. São Paulo: Cortez, 2001.

MORAES, R.; GALIAZZI, M. do C.; RAMOS, M.G. Pesquisa em sala de aula: fundamentos e pressupostos. In: MORAES, R.; LIMA, V.M. do R. Pesquisa em sala de aula: tendências para a educação em novos tempos. Porto Alegre: EDIPUCRS, 2002.

MORAES, R.; RAMOS, M.G.; GALIAZZI, M.C. Pesquisar e aprender em Educação Química: Alguns pressupostos teóricos. 2004. 
RIO GRANDE DO SUL. Secretaria de Estado da Educação. Proposta Pedagógica para o Ensino Médio Politécnico e Educação Profissional Integrada ao Ensino Médio (2011-2014). Porto Alegre, 2011

RODRIGUEZ, A. HÉRAN, C. A. A educação secundária no Brasil: chegou a hora.1. ${ }^{\text {a }}$ ed. Waschington, D. C.: Banco Interamericano de Desenvolvimento-Banco Mundial, 2000 .

RODRIGUES, E. M. "Ensino noturno de 2. ${ }^{\circ}$ grau: o fracasso da escola ou a escola do fracasso". Educação e Realidade, v. 20, n. ${ }^{\circ}$ 1, jan/jun, 1995.

SPOSITO, M. P. Trabalhador-estudante: um perfil do aluno do curso superior noturno. São Paulo: Loyola, 1989.

TOGNI A. C, SOARES M. J. A escola noturna de ensino médio no Brasil. Rev Iberoamericana Educ. p.44: 61-76, 2007.

WALLON, H. A Evolução psicológica da criança. $2^{\mathrm{a}}$ ed. São Paulo: Martins Fontes, 2010.

VYGOTSKY, L. S. A construção do pensamento e da linguagem. São Paulo: Martins Fontes 2001.

\section{Como referenciar este artigo:}

MICHELS, Josué; BARBOSA, Gabriela; FARIAS, Maria Eloísa. Educar pela pesquisa na disciplina de seminário integrado: um olhar diferenciado sobre o ensino médio noturno. Revista Ibero-Americana de Estudos em Educação, Araraquara, v. 12, n. 2, p. 933-951, 2017. Disponível em: <http://dx.doi.org/10.21723/riaee.v12.n2.8737>. EISSN: 1982-5587.

Recebido em: 24/06/2016

Aprovação final em: 30/03/2016 